\title{
Novas mudanças no financiamento ou velhos condicionantes políticos? Um estudo sobre as 4 deputadas estaduais eleitas no Paraná em 2018
}

\author{
New changes in political finance or old political constraints? A study on the 4 state deputies \\ elected in Paraná in 2018
}

\author{
Luiz Fernando Zelinski ${ }^{1}$ \\ Eduardo Soncini Miranda ${ }^{2}$ \\ Maria Cecília Eduardo ${ }^{3}$
}

\begin{abstract}
Resumo
Recentemente, um conjunto de alterações no desenho institucional eleitoral tratou sobre o financiamento de campanhas e incentivo à participação feminina. Sob as novas regras, o que se viu nas eleições de 2018 no estado do Paraná foi que das 54 cadeiras em disputa para a Assembleia Legislativa, quatro foram ocupadas por mulheres. Para melhor compreender o sucesso eleitoral dessas candidatas, neste material propomos uma combinação de análise que ocorreu em duas frentes: uma analisa o sucesso eleitoral por meio do financiamento eleitoral das candidaturas; a outra, analisa as estruturas de parentesco familiar dessas candidaturas como um elemento fundamental ao sucesso eleitoral. Os primeiros achados se mostram promissores, visto que as variáveis encontram respaldo na literatura como elementos fundamentais para o sucesso eleitoral. No entanto, consideramos a necessidade de promover uma discussão sobre como melhorar a combinação dessas análises, sobretudo no aspecto de métodos e técnicas para o alcance de resultados fidedignos.
\end{abstract}

Palavras-chave: Financiamento eleitoral. Famílias. Eleições.

\begin{abstract}
Recently, a number of changes in the electoral institutional design dealt with campaign financing and encouraging female participation. Under the new rules, in the 2018 elections in the state of Parana, what we saw was 54 seats in the race for the Legislative Assembly, four were occupied by women. To better understand the electoral success of these candidates, this material proposes a combination of analysis that takes place on two fronts: an analysis of electoral success through the electoral financing of candidates and the family-related structures of these candidacies as a key element in electoral success. The first results found were promising, seen that the respected variables in the literature as fundamental elements for electoral success. However, we consider the need to promote a discussion on how to improve the combination of these statistics, especially the aspect of methods and techniques for achieving reliable results.
\end{abstract}

Keywords: Electoral financing. Families. Elections.

\footnotetext{
${ }^{1}$ Mestrando em Ciência Política (PPGCP-UFPR). E-mail: fernandozelinski@ufpr.br.

${ }^{2}$ Doutor em Ciência Política (PPGCP-UFPR). E-mail: eduardomiranda@ufpr.br.

${ }^{3}$ Doutoranda em Ciência Política (PPGCP-UFPR). E-mail: mceduardo9@ gmail.com.
} 


\section{Introdução}

Nas eleições estaduais de 2018, das 54 cadeiras em disputa na Assembleia Legislativa do Paraná (ALEP), 50 foram ocupadas por homens e apenas 4 por mulheres. Números pouco superiores aos da eleição de 2014, quando 51 cadeiras foram conquistadas por homens e 3 por mulheres. Ainda que tímida, seria certo apontar a mudança promovida no estado do Paraná como resultado das recentes mudanças no desenho institucional eleitoral?

Recentemente, duas "minirreformas eleitorais", em 2015 e 2017, alteraram regras fundamentais no que se refere ao financiamento eleitoral de campanhas, na distribuição de recursos públicos e na composição das chapas eleitorais. A primeira, a "minirreforma eleitoral de 2015", estabelecida pela Lei $\mathrm{n}^{\circ} 13.165 / 15$, passou a proibir a doação direta e indireta de empresas para partidos políticos e candidatos, respeitando a decisão proferida pelo Supremo Tribunal Federal (STF) na Ação Direta de Inconstitucionalidade (ADI) n 4.650. A mesma lei também promoveu alterações na lei das eleições ao estabelecer que "cada partido ou coligação preencherá o mínimo de 30\% (trinta por cento) e o máximo de 70\% (setenta por cento) para candidaturas de cada sexo" (artigo 10, parágrafo $3^{\circ}$ da Lei $\left.n^{\circ} 9.504 / 97\right)$, buscando assim promover incentivos à participação feminina. A segunda, a "minirreforma eleitoral de 2017", estabelecida pela Lei n ${ }^{\circ} 13.488 / 17$, criou o Fundo Especial de Financiamento de Campanhas (FEFC) que aportou, segundo o Tribunal Superior Eleitoral (TSE), cerca de 1,7 bilhão de reais nas eleições de 2018 em todo o país. Na esteira desses eventos, o TSE estabeleceu que 30\% do dinheiro do FEFC e do já tradicional Fundo Partidário, se direcionados para campanhas, deveriam ser aportados no financiamento de suas candidatas (Resolução $n^{\circ} 23.553 / 2017$ e Resolução no 23.575/ 2018).

Uma expectativa que se cria mediante esse contexto é de que a soma dessas alterações pudesse promover condições para o aumento da representatividade de mulheres nos cargos políticos em disputa por todo o Brasil nas eleições de 2018. Segundo dados do TSE, em relação a 2014, para a Câmara de Deputados ocorreu um aumento de 51\% de parlamentares eleitas, saindo de 51 para 77 de um total de 513 cadeiras. Nas Assembleias Legislativas dos estados, o crescimento foi de 41,2\% em relação a 2014, quando 114 mulheres foram sido eleitas, e em 2018, 161 mulheres foram eleitas.

No Paraná, a variação percentual foi positiva em 33\% para a ocupação da Assembleia Legislativa do Estado do Paraná (ALEP), no entanto, abaixo da média nacional. A ALEP possui 54 cadeiras e em 2014, a bancada feminina era composta por três deputadas estaduais: Cantora Mara Lima (PSC), Claudia Pereira (PSC) e Maria Victoria (PP). Com as eleições de 2018 foram eleitas 
quatro candidatas: Maria Victoria (PP) reeleita, Cristina Silvestri (PPS), Mabel Canto (PSC) e Luciana Rafagnin (PT).

Para avaliar como as novas regras eleitorais impactaram nas campanhas das mulheres nas eleições de 2018 no estado do Paraná, investigamos as candidaturas à ALEP sob dois aspectos: primeiro, sobre a forma de distribuição e composição das receitas de campanhas dos candidatos, sobretudo no aspecto entre financiamento público e privado; segundo, nos dedicamos a compreender o background familiar das candidatas eleitas como um elemento alternativo ao sucesso eleitoral das candidatas.

\section{Metodologia}

Para a execução deste trabalho, foram realizados dois processos metodológicos, um de caráter mais quantitativo e outro mais qualitativo. Para o trabalho de caráter quantitativo, optou-se por um conjunto de ferramentas que permitiu coletar, identificar, minerar e categorizar os vários tipos de doações que compõem as receitas dos candidatos que disputaram os cargos de Deputado Estadual. Para tanto, a fonte oficial de dados é o site do Repositório de Dados Eleitorais do Tribunal Superior Eleitoral (TSE), onde se realizou o download de dois tipos de bancos de dados entre os disponíveis: a) Consultacand, que apresenta dados pessoais de candidatura do candidato; e b) Prestação de contas dos candidatos, que apresenta as receitas e despesas relativas a doações eleitorais.

Devido ao tamanho dos bancos de dados utilizamos o software DB Browser, que por meio de linguagem em SQL (Structured Query Language) nos permitiu extrair as informações de doações relativas ao cargo estudado. A fim de produzir maior fidedignidade no estudo, para ambos os bancos optamos por trabalhar apenas com os candidatos que tiveram a candidatura deferida (candidaturas deferidas e deferidas com recurso) pela justiça eleitoral.

Consideramos para este estudo como Recursos Públicos a soma das doações que tem como fonte o Fundo Especial de Financiamento de Campanha (FEFC) e o Fundo Partidário. Ademais, são recursos privados as doações advindas de pessoas físicas e dos próprios candidatos. Em um segundo momento, importamos as informações acima no software Excel, em que no banco de dados do Consultacand, que apresenta variáveis de cunho individual de cada candidato como Nome, Nome de Urna, Número de Urna, Partido, Sexo, Idade, se eleito ou não eleito, agregamos variáveis que são a soma total das receitas por Fonte e Origem das doações. Utilizamos o software Tableau para as 
análises de distribuição de receitas por gênero e resultados eleitorais dos candidatos, bem como para a produção de gráficos.

Um segundo método, de caráter qualitativo, consiste em analisar as biografias coletivas das candidatas eleitas, buscando, assim, estudar as origens histórico-familiares das deputadas estaduais eleitas em 2018 no Paraná. Através do método prosopográfico, investigamos as conexões históricas entre os membros/pessoas ligadas às famílias políticas tradicionais e o aparelho do Estado em sua mais diversa dimensão (cargos eletivos ocupados, cargos comissionados, presença de familiares no executivo, legislativo, tribunais de contas, poder judiciário, ministério público, cartórios, entre outros). "O propósito da prosopografia é dar sentido à ação política, ajudar a explicar a mudança ideológica ou cultural, identificar a realidade social e descrever e analisar com precisão a estrutura da sociedade e o grau e a natureza dos movimentos em seu interior” (STONE, 2011, p. 116). A teoria do nepotismo (OLIVEIRA, 2012) vem há anos explicitando as ações de grupos familiares nas instituições políticas, seus impactos na formação de redes de interesse e na formulação de políticas públicas.

Nosso objetivo é mostrar de que maneira as estruturas de parentesco influenciam também na disputa eleitoral, tanto por recursos quanto por votos, e os impactos desse processo para a representação política e para a qualidade da democracia.

\section{Financiamento eleitoral e capital político nas eleições para a ALEP 2018}

É bem verdade que campanhas eleitorais mobilizam muito dinheiro, doações que são de cunho público (FEFC e o tradicional Fundo Partidário) ou privado (sobretudo doações de pessoas física e autodoações dos candidatos) para o custeio de bens e serviços prestados aos candidatos. Sendo assim, é comum a aplicação dos recursos na contratação e aquisição de material de publicidade e propaganda, ou mesmo combustível e aluguel de automóveis.

A justiça eleitoral do Paraná deferiu nas eleições de 2018 um total de 705 candidaturas ao cargo de Deputado Estadual, sendo 487 homens e 218 mulheres, representando, respectivamente, $69 \%$ e $31 \%$. A soma das receitas alcançou valores pouco superiores a 52 milhões de reais, valores estes declarados ao TSE. Desse total, 20,6 milhões, cerca de 40\%, é recurso público, e 31,6 milhões, cerca de $60 \%$, é recurso privado. Desse total, homens recebem 29,6 milhões de recursos privados e 12 milhões de recursos públicos. Mulheres recebem 2 milhões em recursos privados e 8,5 milhões 
em recursos públicos. O mesmo padrão não é observado quando os recursos são tratados pela média dos candidatos.

FIGURA 1 - VALOR MÉDIO DE FINANCIAMENTO POR GÊNERO NAS ELEIÇÕES PARA DEPUTADO ESTADUAL NO PARANÁ 2018

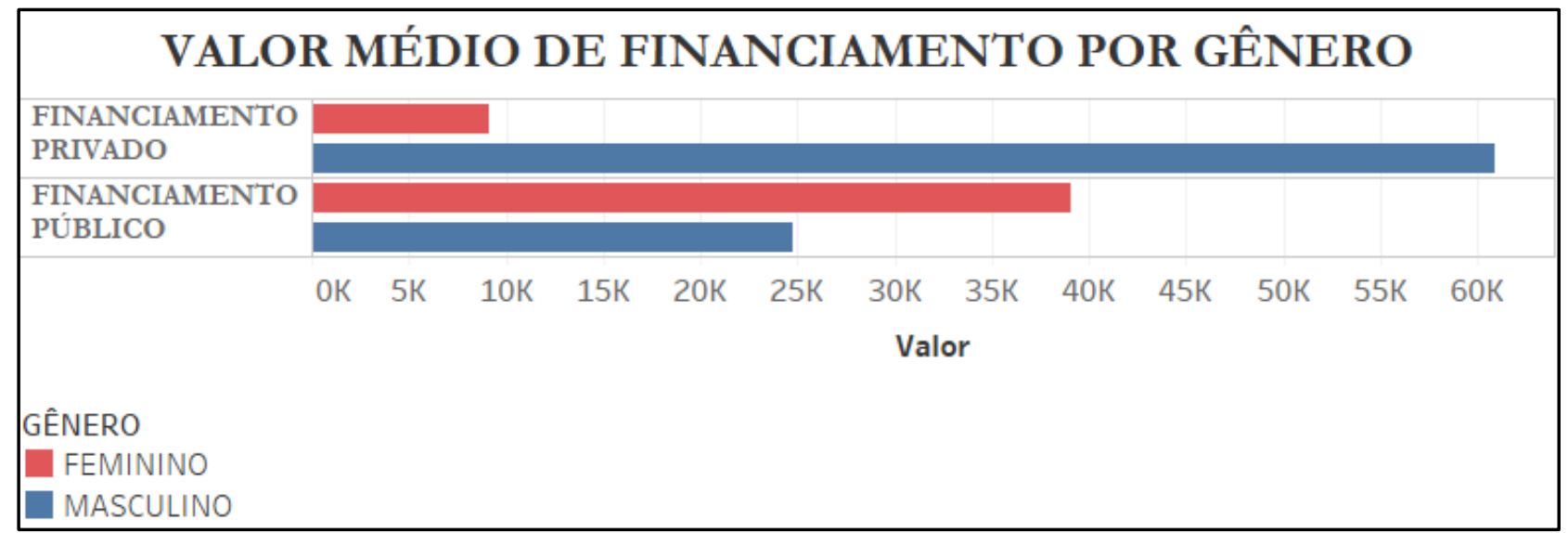

FONTE: Adaptado de TSE (2019).

A questão que se apresenta está na forma como que esse dinheiro é distribuído pelos partidos políticos, ou como são conquistados pelos candidatos para que adquiram bens e serviços que lhes permitam alcançar seu eleitorado e, consequentemente, transformar esse investimento em voto. Fatalmente, a análise final da distribuição de recursos por gênero e por resultado eleitoral, ou seja, candidatos eleitos e não eleitos, revela uma distância muito grande entre esses candidatos que poderia ser explicada por outros elementos que não estão envoltos nas questões tratadas pelas recentes reformas eleitorais.

A média de recursos públicos e privados investidos nas campanhas das quatro candidatas eleitas é 10 vezes superior ao das candidatas não eleitas, ultrapassando a média de 327,4 mil reais em recursos públicos e 83 mil em recursos privados. Nas candidaturas masculinas, homens eleitos recebem 3,5 vezes mais recursos públicos que não eleitos, enquanto a média de recursos privados entre os eleitos é 8 vezes mais que o de não eleitos. 
FIGURA 2 - MÉDIA DE FINANCIAMENTO ENTRE ELEITOS E NÃO ELEITOS POR GÊNERO NO PARANÁ EM 2018

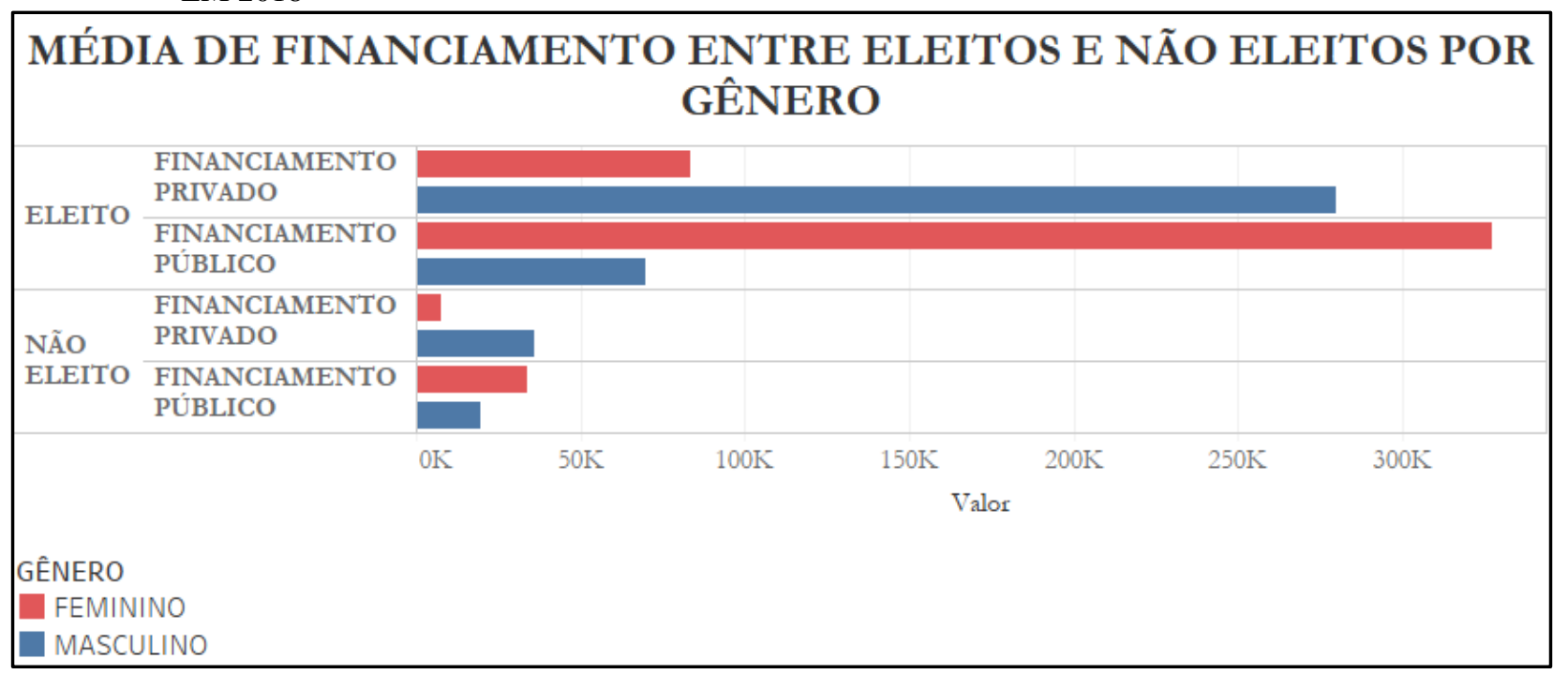

FONTE: Adaptado de TSE (2019).

Olhamos mais de perto a composição das receitas das candidatas eleitas e analisando aspectos de capitais políticos familiares, buscamos pesquisar como a soma desses elementos podem ajudar a compreender melhor o resultado eleitoral no Paraná em 2018.

A deputada estadual Maria Victória (PP), única reeleita, conquistou seu segundo mandato na ALEP com 50.414 votos em 2018. A candidata apresentou receitas que alcançam 915 mil reais e desse total, 890 mil são recursos públicos, 75\% advindo do PP Nacional, 9,6\% do PP Estadual e 12,5\% do DEM Nacional. Dentre as mulheres de seu partido, é a mais bem financiada. Maria Victória é atual presidente do PP paranaense e filha do ex-ministro da saúde do governo Michel Temer, Ricardo Barros (PP), e de Cida Borghetti (PP), vice-governadora do Paraná no governo Beto Richa.

A deputada estadual Isabel Cristina Rauen Silvestri (PPS) foi eleita com um total de 48.805 votos, somando pouco mais de 520 mil reais, destes, 320 mil, cerca de 61\%, são recursos públicos (de longe a mais bem financiada por recursos públicos entre as mulheres de seu partido). Destes 320, 70 mil advêm de doações realizadas pelo comitê do candidato a deputado federal eleito Rubens Bueno, presidente do PPS à época da eleição. Transferências de recursos entre candidatos é uma prática comum em campanhas eleitorais e podem dar sinais de candidatos que buscam juntos estratégias de votos em uma mesma região. A deputada Cristina Silvestri vem de uma família com um importante histórico político na cidade de Guarapuava. Foi esposa do recentemente falecido Cezar Augusto Carollo Silvestri, que já foi vice-prefeito de Guarapuava, deputado estadual (eleito em 1990, 1994 e 1998) e deputado federal pelo Paraná (2002, 2006 e 2010) pelo Partido Popular Socialista (PPS). O filho do casal é Cesar Silvestri Filho, ex-deputado estadual e atual prefeito de Guarapuava. 
Luciana Rafagnin (PT) foi eleita com 30.931 votos, declarando uma quantia próxima a 120 mil reais, dos quais 99 mil, cerca de 80\%, são recursos públicos. Como suas demais colegas citadas, também foi a mais financiada entre as candidatas de seu partido e conta com doações dos comitês da candidata ao senado Mirian Gonçalves e candidata à deputada federal Gleisi Hoffmann, advindo desta última 50 mil reais. Rafagnin é cientista política e agricultora familiar. Casada com Justino Rafgnin (dirigente do PT), a deputada estadual foi anteriormente vereadora em Francisco Beltrão/PR por dois mandatos, elegendo-se em 1992 e em 1996, bem como exerceu de forma consecutiva três mandatos como Deputada Estadual na Assembleia Legislativa do Paraná em 2002, 2006 e 2010.

A deputada estadual Mabel Canto (PSC) foi eleita com um total de 35.036 votos, declarando um total de $\mathrm{R} \$ 84.250,91$ totalmente compostos por recursos privados. A candidata é a única mulher de seu partido a não receber fundos públicos para a realização de sua campanha. O PSC lançou outras 11 candidatas, que somadas receberam aproximadamente 1,4 milhão de reais. Destes, cerca de 300 mil foram para a candidata Claudia Pereira e 200 mil para a candidata Cantora Mara Lima, ambas eleitas em 2014 com uma carreira política já consolidada. Recentemente, a deputada Cantora Mara Lima assumiu como suplente a vaga deixada pelo deputado estadual Guto Silva (PSD). A deputada Mabel Canto é filha do radialista Jocelito Canto, ex-deputado estadual e ex-prefeito de Ponta Grossa.

FIGURA 3 - FINANCIAMENTO EM VALORES ABSOLUTOS DAS CANDIDATAS ELEITAS NO PARANÁ EM 2018

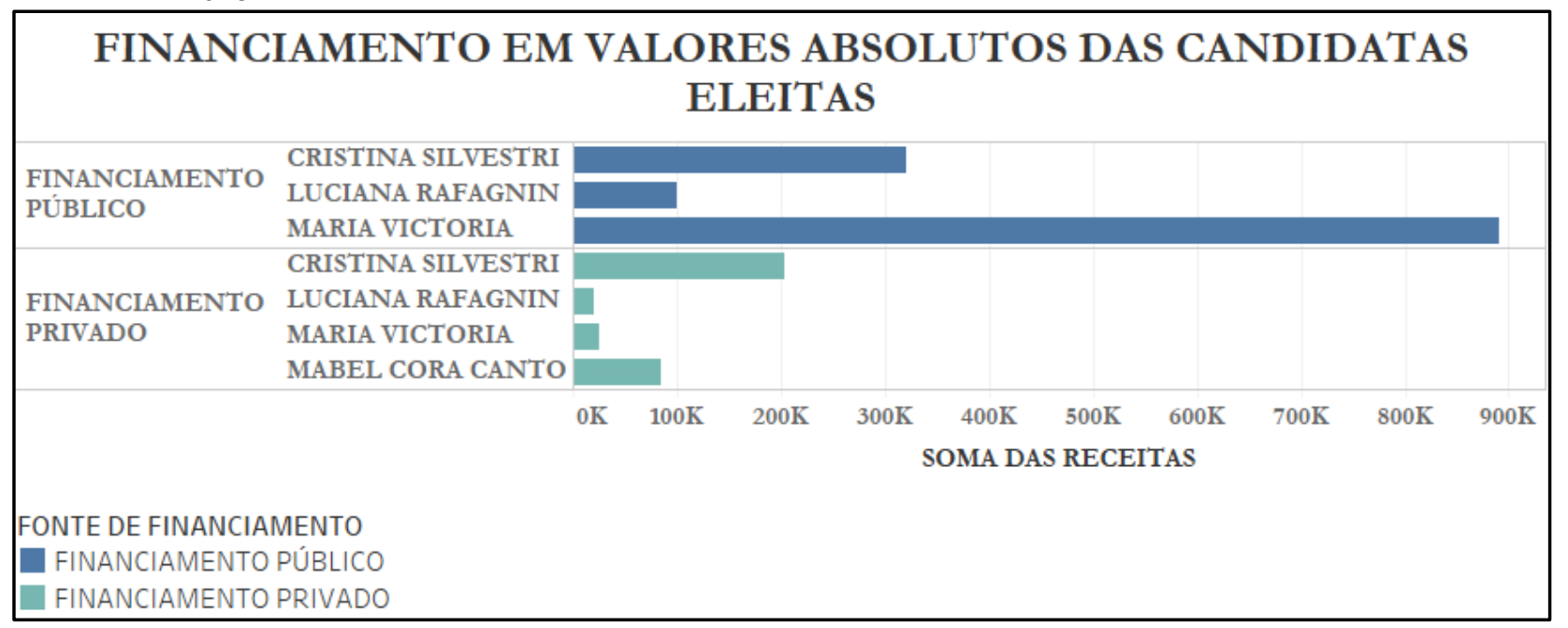

FONTE: Adaptado de TSE (2019).

Por fim, a lei estabelece que 30\% na cota de "participação" em chapas eleitorais foi cumprida; o mesmo acontece para os recursos públicos empregados em campanhas de mulheres. O que não significa igualdade na distribuição dos recursos públicos, pois a distribuição pode ser realizada de forma arbitrária e estar atrelada a interesses políticos e estratégicos do partido. 
Dessa forma, os dados sobre as doações eleitorais corroboram a retórica de que o dinheiro é elemento fundamental em uma eleição e que desigualdade econômica gera desigualdade política (PRZEWORSKI, 2012). Sobretudo, vimos que para compreender o resultado eleitoral no Paraná, é preciso ir além da seara do financiamento eleitoral de campanhas e das regras de participação. Capital político importa e é elemento fundamental para o sucesso de candidatas. Não obstante, é cabível, desde sempre, que políticos, legisladores, cientistas e sociedade civil mantenham constante o debate para as melhorias nas regras que sustentam o jogo eleitoral, sobretudo em regras que cercam a questão da representatividade eleitoral.

FIGURA 4 - ORIGEM DO FINANCIAMENTO PÚBLICO POR PARTIDO DOADOR OU COMITE DAS CANDIDATAS ELEITAS À DEPUTADA ESTADUAL NO PARANÁ EM 2018

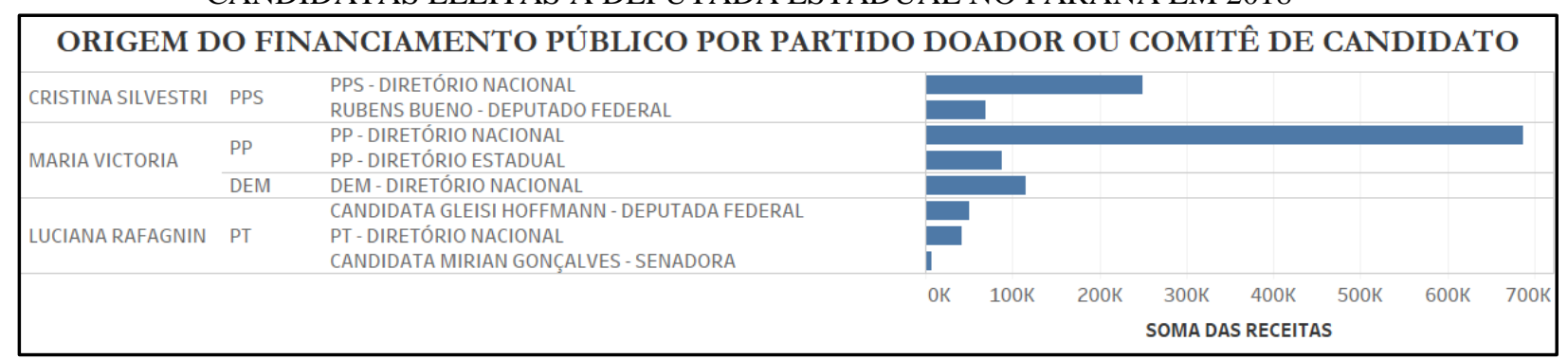

FONTE: Adaptado de TSE (2019).

\section{Quem são as quatro candidatas eleitas?}

Apesar de serem a maioria da população brasileira, as mulheres estão longe de figurarem como a maioria nas instituições políticas brasileiras. Segundo dados da PNAD 2018 (Pesquisa Nacional por Amostra de Domicílios Contínua), a população brasileira é composta por cerca de 210 milhões de pessoas, sendo 51,7\% de mulheres e 48,3\% de homens. De acordo com o TSE, o Brasil possui mais de 77 milhões de eleitoras, o que representa 52,5\% do total de 147,5 milhões de eleitores. Desse número, apenas 9.204 (31,6\%) mulheres concorreram a um cargo eletivo nas eleições de 2018. Destas, 290 foram eleitas, um aumento de 52,6\% em relação a 2014.

No Paraná, a população estimada é de cerca de 11 milhões de pessoas. Os eleitores paranaenses são formados por cerca de oito milhões de pessoas, sendo 52,4\% dos eleitores mulheres, enquanto 47,6\% são homens. Seguindo uma tendência nacional, o número de mulheres eleitas para os cargos de deputado federal e estadual aumentou nas eleições de 2018 no Paraná. Na ALEP, a bancada feminina cresceu de três para quatro deputadas em 2018. Portanto, as mulheres representam $7 \%$ dos 54 deputados estaduais paranaenses atuais. 
Em 2014, a bancada feminina era composta pelas deputadas estaduais: Cantora Mara Lima (PSC), Claudia Pereira (PSC) e Maria Victoria (PP). Com as eleições de 2018, a bancada feminina passou a ser composta pelas deputadas: Maria Victoria (PP), Cristina Silvestri (PPS), Mabel Canto (PSC) e Luciana Rafagnin (PT).

Percebemos que desde 2014, a maioria das deputadas eleitas para a ALEP pertencem a famílias políticas tradicionais. São os casos de Claudia Pereira (PSC) e Maria Victoria (PP), única deputada reeleita. Em 2018, a ligação das deputadas eleitas com famílias políticas tradicionais se manteve: das quatro deputadas eleitas, três são oriundas de famílias políticas, como nos casos de Maria Victoria (PP), Cristina Silvestri (PPS) e Mabel Canto (PSC).

\section{Maria Victoria}

Única reeleita, a deputada estadual Maria Victória (PP) conquistou seu segundo mandato na ALEP com 50.414 votos em 2018. Atualmente, é a presidente do PP paranaense, sendo também, além de deputada estadual, empresária, bem como já havia tentado ser prefeita da capital do Paraná. Ela disputou as eleições municipais em 2016, quando tinha apenas 27 anos, ficando em $4^{\circ}$ lugar, com 52.576 votos, ou seja, 5,6\% do total dos eleitores de Curitiba. Maria Victoria é filha do ex-ministro da saúde do governo Michel Temer, Ricardo Barros (PP), e de Cida Borghetti (PP), vice-governadora do Paraná no governo Beto Richa.

Cida Borghetti disputou o governo do estado, ficando em segundo lugar nas eleições de 2018. A primeira candidatura de Cida Borghetti foi em 2000, quando disputou a Prefeitura Municipal de Maringá pelo PP, obtendo 22.931 votos, ficando em quarto lugar. Dois anos após, em 2002, foi candidata à Deputada Estadual, dobrando com o marido - o então candidato a Deputado Federal -, obtendo 53.225 votos e elegendo-se. Em 2006, foi novamente candidata, sendo eleita com 66.492 votos. A última candidatura ocorreu em 2010, quando disputou uma vaga para a Câmara dos Deputados, elegendo-se com 147.910 votos. Em 2014, foi eleita vice-governadora na chapa com Beto Richa e em 2018 disputou o governo do Paraná, sendo derrotada no primeiro turno por Ratinho Jr. (PSD).

A família Barros está presente na política maringaense desde a criação do município. O avô de Maria Victoria era Silvio Magalhães Barros, que foi vereador suplente durante a legislatura de 1960 a 1964, representando a UDN (União Democrática Nacional). Em 1966, foi eleito deputado estadual e em 1970 foi eleito deputado federal pelo MDB (Movimento Democrático Brasileiro). Foi ainda prefeito de Maringá em 1972. Casado com Bárbara Cecily Barros tiveram dois filhos que se tornariam futuros políticos paranaenses: Ricardo José Magalhães Barros e Silvio Magalhães Barros 
II. Ricardo José Magalhães Barros nasceu em 1959. Sua carreira política iniciou-se em 1988, quando foi candidato e eleito prefeito de Maringá com 38.902 votos. Ricardo Barros também foi candidato a Deputado Federal em 1994, ainda pelo Partido da Frente Liberal (PFL), obtendo 54.049 votos. Já em 1998, foi reeleito Deputado Federal pelo Partido Progressista Brasileiro (PPB), atual Partido Progressista, ao qual se mantém filiado até hoje. Com 68.919 votos, ampliou o eleitorado e foi consolidando o posto de Deputado Federal de Maringá e região. Ricardo Barros reelegeu-se para o terceiro mandato em 2002, com 118.036 votos. Em 2006, com 130.085 votos, foi eleito para o quarto mandato consecutivo. Em 2010, Barros disputou e perdeu a cadeira ao Senado pelo PP. Após a derrota, Barros foi indicado para assumir a Secretaria Estadual da Indústria, do Comércio e de Assuntos do Mercosul no governo Beto Richa. Com o processo de impeachment de Dilma Rousseff (PT), Michel Temer (MDB) indicou Ricardo Barros para ser o Ministro da Saúde. O tio de Maria Victoria é Silvio Magalhães Barros II, nascido em 1956. Sílvio disputou a prefeitura de Maringá pela primeira vez em 1996, obtendo 31.081 votos pelo PFL. Foi eleito pela primeira vez em 2004 pelo PP, obtendo 43.333 votos no primeiro turno e 92.052 no segundo turno para a prefeitura maringaense. Reeleito em 2008, obteve 104.820 votos, representando 57\% do eleitorado.

\section{Cristina Silvestri}

A deputada estadual Isabel Cristina Rauen Silvestri (PPS) é filha de Eurípio Rauen, ex-vereador de Guarapuava e bisneta de Frederico Virmond e Romualdo Baraúna. As famílias Virmond e Baraúna são seculares na região, sendo que Frederico Guilherme Virmond Junior foi deputado ainda no século XIX. Romualdo Antônio Baraúna foi Prefeito de Guarapuava e Deputado Estadual na década de 1920. A Deputada Cristina Rauen Silvestri era esposa do recentemente falecido Cezar Augusto Carollo Silvestri, engenheiro civil do Departamento de Estrada e Rodagem (DER/PR), formado pela Universidade Federal do Paraná em 1977. Cesar ingressou na vida pública em 1988, quando foi eleito Vice-prefeito de Guarapuava e também exerceu três mandatos como Deputado Estadual, sendo eleito três vezes consecutivas: 1990, 1994 e 1998. Em 2002, Silvestri foi eleito Deputado Federal pelo Paraná, cargo para o qual foi reeleito nas duas eleições seguintes: em 2006 e 2010 pelo Partido Popular Socialista (PPS). Também foi Secretário de Estado do Desenvolvimento Urbano (Sedu), no primeiro mandato do governador Beto Richa. Em 2013, foi nomeado Secretário de Governo e logo depois, assumiu o cargo de Secretário-chefe da Casa Civil. Em 2015, assumiu a presidência da Agência Reguladora de Serviços Públicos Delegados de Infraestrutura do Paraná (Agepar). Seu pai era Moacyr Júlio Silvestre, Prefeito de Guarapuava pelo PTB entre 1960 e 1962, Deputado Estadual pelo PTB entre 1963 e 1966, Deputado Federal pela ARENA entre 1967 e 1969, 
novamente Prefeito de Guarapuava pela ARENA entre 1969 e 1972. O filho da Deputada Cristina Silvestri é Cesar Silvestri Filho (PPS), atual Prefeito de Guarapuava. Cesar Filho foi Vice-presidente da juventude do Partido Popular Socialista (PPS) e assessor do presidente nacional do partido, Senador Roberto Freire. Disputou sua primeira eleição aos 27 anos, em 2008, para a prefeitura de Guarapuava, obtendo mais de 34 mil votos. Dois anos depois, foi eleito Deputado Estadual. Nas eleições para prefeito de Guarapuava em 2012 foi eleito com 51.425 votos; em 2016, foi reeleito para o cargo com $60 \%$ dos votos.

\section{Mabel Canto}

Mabel Canto (PSC) foi eleita Deputada Estadual com 35.036 (0,62\% dos válidos) nas eleições de 2018. É mãe de dois filhos, tem 34 anos, é advogada formada pelo Cescage e graduanda em Direito Administrativo pela UEPG.

No site oficial da deputada estadual Mabel Canto, percebemos a ligação da deputada com seu pai, Jocelito Canto, radialista e ex-Deputado Estadual e ex-Prefeito de Ponta Grossa. Já no item "minha história" extraímos o seguinte trecho: "Eu sou Mabel Canto, tenho 33 anos, nasci em Clevelândia no sudoeste do estado, mas sou pontagrossense de coração há mais de 26 anos. Desde os meus 15 anos sigo os passos do meu pai como radialista. Atualmente, além da advocacia, sou uma das apresentadoras do programa O Repórter pela Difusora FM junto com o Jocelito e minha irmã Joce. Na prefeitura ajudei ativamente no Serviço de Obras Sociais, no período em que minha mãe Marilu foi presidente, atendendo às pessoas que mais precisavam e participei de programas sociais que me deram oportunidade de conhecer a realidade de todos os bairros da cidade. De 2003 a 2010, durante os mandatos de meu pai como deputado estadual, estive junto com ele na Assembleia Legislativa atendendo toda a região dos Campos Gerais. Posteriormente trabalhei como assessora jurídica na Secretaria de Segurança Pública do Estado e atuei como a técnica responsável pela gerência do Programa Leite das Crianças na região dos Campos Gerais”.

Seu pai, Jocelito Canto, é um radialista, apresentador de televisão e ex-Deputado Estadual. Iniciou sua vida profissional no rádio no Rio Grande do Sul. Passou por emissoras de Santa Catarina e ainda no sudoeste do Paraná. Muda-se para Ponta Grossa, onde fixou residência em 1992. Já em 1994 foi eleito Deputado Estadual pelo Partido Social Cristão (PSC). Em 1996 foi eleito Prefeito em Ponta Grossa pelo Partido da Social Democracia Brasileira (PSDB). Em 2000, concorreu à reeleição, não sendo reeleito. Em 2002 foi eleito novamente Deputado Estadual, pelo Partido Republicano Progressista (PRP). Em 2006, foi reeleito para a Assembleia Legislativa, dessa vez pelo Partido Trabalhista Brasileiro (PTB). Atualmente, atua na Rede Massa, afiliada do SBT no Paraná, 
apresentando o programa Tribuna da Massa para Ponta Grossa, mas também em outras cidades dos Campos Gerais e do sul e sudoeste do estado. Ele também apresenta o programa O Repórter pela Rádio Difusora, tradicionalmente pela "Garagem da Esperança".

\section{Luciana Rafagnin}

A deputada estadual Luciana Rafagnin (PT) é cientista política e agricultora familiar. Nascida em Mariano Moro (RS), começou sua caminhada de atuação pelos movimentos sociais do Sudoeste paranaense, especialmente na organização das mulheres e no sindicato dos trabalhadores rurais de Francisco Beltrão. É filha de Tranqüilo Guzella e Dejanira Chiapetti Guzella. Casada com Justino Rafgnin (dirigente do PT) tem dois filhos: Camilo e Giovana. A deputada Luciana Rafagnin foi anteriormente Vereadora em Francisco Beltrão por dois mandatos, elegendo-se em 1992 e 1996. Exerceu de forma consecutiva três mandatos como Deputada Estadual na Assembleia Legislativa do Paraná, elegendo-se em 2002, 2006 e 2010. Disputou a eleição de 2014, mas não foi eleita. Em 2018 foi eleita Deputada Estadual com 30.813 votos. É filiada ao PT desde 1989.

\section{Considerações finais}

Os resultados do trabalho demonstram que existe uma relação positiva entre financiamento de campanha, sobretudo público, com o background familiar das candidatas, ainda que não seja possível neste momento demonstrar a relação causal direta entre as variáveis.

É neste elemento que se encontra o maior desafio deste trabalho e é onde pretendemos contribuir com a literatura. Logo, o estabelecimento de uma agenda de estudo que vise perscrutar e ampliar a compreensão da relação entre dinheiro, sucesso eleitoral e estruturas/redes de parentesco e nepotismo se faz necessário. Tendo essas relações como elemento central, procura-se desenvolver ou buscar na literatura um conjunto de métodos e técnicas que permitam alcançar resultados fidedignos.

Os estudos sobre financiamento de campanhas e relações familiares para o sucesso eleitoral de candidatos se mostram um campo promissor. Acredita-se que esse campo se beneficiaria das técnicas de análise de redes sociais (ALVES, 2017; GEARA et al., 2018; HOROCHOVSKI et al., 2015; HOROCHOVSKI; JUNCKES et al., 2016; HOROCHOVSKI; JUNKES et al., 2016; JUNCKES; HOROCHOVSKI; CAMARGO, 2016; JUNCKES et al., 2019). 


\section{Referências}

ALVES, M. Redes de campanha na eleição do Rio de Janeiro em 2016. Compolítica, v. 7, n. 2, p. 87-120, 18 nov. 2017. Disponível em:

http://compolitica.org/revista/index.php/revista/article/view/308. Acesso em: 8 jan. 2018.

BRASIL. TRIBUNAL SUPERIOR ELEITORAL. Resolução n 23.553. Dispõe sobre a arrecadação e os gastos de recursos por partidos políticos e candidatos e sobre a prestação de contas nas eleições. [S.l: s.n.]. Disponível em: http://www.tse.jus.br/legislacao-tse/res/2017/RES235532017.html. Acesso em: 19 fev. 2019.

BRASIL. TRIBUNAL SUPERIOR ELEITORAL. Resolução n 23.575/2018. Altera a Resolução TSE $n^{\circ} 23.553$, de 18 de dezembro de 2017, que dispõe sobre a arrecadação e os gastos de recursos por partidos políticos e candidatos e sobre a prestação de contas nas eleições. Disponível em: http://www.tse.jus.br/legislacao-tse/res/2018/RES235752018.html. Acesso em: 20 maio 2019.

GEARA, L. E. et al. O financiamento eleitoral nas comissões permanentes da Câmara dos Deputados: uma análise do meta relacionamento entre empresas e parlamentares. E-legis, p. 60-81, 2018.

GRANATO, N. C. Famílias políticas tradicionais nas eleições à prefeitura de Guarapuava em 2016. Revista NEP (Núcleo de Estudos Paranaenses), Curitiba, v. 2, n. 4, p. 51-56, set. 2016.

HOROCHOVSKI, R. R.; JUNKES, I. J. et al. Estruturas de poder nas redes de financiamento político nas eleições de 2010 no Brasil. Opinião Pública, v. 22, n. 1, p. 28-55, abr. 2016.

HOROCHOVSKI, R. R. et al. Redes de partidos políticos tecidas por financiadores: um estudo das eleições de 2010 no Brasil. Teoria \& Sociedade, v. 23, n. 2, p. 49-78, 2015. Disponível em: http://www.din.uem.br/sbpo/sbpo2016/pdf/156426.pdf.

HOROCHOVSKI, R. R.; JUNCKES, I. J. et al. Um modelo para capturar a relação entre financiamento eleitoral e contratação de bens e serviços: o caso de Curitiba. The Observatory of Social and Political Elites of Brazil, v. 3, n. 3, 2016. Disponível em: http://observatoryelites.org/wp-content/uploads/2012/06/newsletter-Observatorio-v.-3-n.-3.pdf. Acesso em: 25 jul. 2017.

JUNCKES, I. J.; HOROCHOVSKI, R. R.; CAMARGO, N. F. Redes de financiadores, partidos políticos e candidatos nas eleições de 2014 no Brasil. $10^{\circ}$ Encontro da Associação Brasileira de Ciência Política, 2016.

JUNCKES, I. J. et al. Poder e Democracia: uma análise da rede de financiamento eleitoral em 2014 no Brasil. Revista Brasileira de Ciências Sociais, v. 34, n. 100, 18 fev. 2019. Disponível em: http://www.scielo.br/scielo.php?script=sci_arttext\&pid=S0102-

69092019000200502\&lng=pt\&tlng=pt. Acesso em: 18 fev. 2019.

MIRANDA, E. S.; ZELINSKI, L. F. Revista NEP (Núcleo de Estudos Paranaenses), v. 5, n. 1, p. 40-77, 28 jun. 2019. Disponível em: https://revistas.ufpr.br/nep/article/view/67658/38944. Acesso em: 15 jul. 2019. 
OLIVEIRA, R. C. Na teia do nepotismo. Curitiba: Insight, 2012.

PEREIRA, F. M. Maria Victoria (PP), herdeira das velhas oligarquias. Disponível em: https://www.brasildefato.com.br/2016/09/26/maria-victoria-pp-herdeira-dasvelhas-oligarquias/. Acesso em: mar. 2019.

PRZEWORSKI, A. Democracy, redistribution, and e equality. Brazilian Political Science Review, v. 6, n. 1, p. 11-36 , 2012. Disponível em: http://www.redalyc.org/articulo.oa?id=394341999001. Acesso em: 17 maio 2019.

STONE, L. Prosopografia. Revista de Sociologia e Política, v. 19, n. 39, 2011.

Artigo recebido em 26/11/2019. Aceito para publicação em 20/12/2019. 